\title{
40 School policy development and creation
}

\author{
Kelly-Ann Allen, Andrea Reupert, Alan Reid, Ian \\ Hardy, and Lindsay Oades
}

As can be seen throughout the book, educational research as a discipline, is on the whole extensive, and accordingly it is well-positioned to guide schools towards evidence-based practices. Rigorous, empirically sound research is only one part of the puzzle. The development of policy is collaborative. This book has provided a foundation for school policy, but the intention is that each policy only comes to life once it has been adapted and agreed upon. It is imperative that each policy is tailored to suit the unique needs and contexts of each school.

We hope that this book paves a strong collaborative partnership between researchers and practitioners, which will ultimately lead to a stronger connection between research and practice.

Although the policies in the book cover an extensive array of topics, we acknowledge that not every possible policy could be included. As such, we encourage schools to create their own policy as needed. Below is a policy template consistent with the other templates in this book that school policymakers may use to create their own policies.

Insert policy name here.

\section{How to use this policy}

Insert a paragraph about why your policy is important and how your policy could be used in meaningful ways.

\section{[INSERT name of school] Name of policy}

\section{Rationale}

Definition of your area and rationale for the importance of this policy in schools. Please link briefly to theory or research here, and throughout your policy to demonstrate the evidence basis of your work. 


\section{Purpose}

Insert a brief statement that summarises the key objective of the policy.

\section{Scope}

Who does this policy apply to and how is it applied?

[Insert specific roles and responsibilities of individuals or teams]

\section{Policy statement}

Outline policy statements in this section based on theory, research, and best practice. This section should be the core body of your policy. Policy statements should be brief and straight to the point. Consider the use of subheadings, if necessary. Subheadings should be italicised and flushed left. Consider keeping policy statements brief and related to practices. Dot points are okay, if required.

\section{Authorship}

Insert your name and contributors to this policy, plus their institutional affiliation [INSERT RELEVANT STAFF MEMBERS].

\section{Related policy and documents}

[INSERT RELEVANT POLICY AND DOCUMENTS]

List some examples of related policy or documents.

\section{Date of ratification}

This policy was ratified on the [INSERT DATE].

\section{Date of review}

This policy will be reviewed by [INSERT DATE].

\section{References}

Insert references here.

\section{Expert consultation}

Insert suggestions for possible consultation that may be required to enact the policy. For example, do some policies require legal advice prior to implementation? Or consultation with particular teams/professionals in the school? 


\section{Additional ideas for creating policy}

\section{Link to vision and mission statements}

Does the policy fit with your priorities as a school?

If not, you may need to recalibrate the policy to ensure it fits with the school climate you have or the one you strive to create. Initiate conversations with teachers, students, parents, and locals to create a consensus around what policies are needed; identify those that are urgent and important; and consider how these policies are aligned with the purpose and priorities of the school.

\section{Ensure a complementary curriculum}

Does the curriculum support the policy proposed and vice versa?

For example, a complementary curriculum will foster the skills, knowledge, and attitudes that ensure the policy is authentically enacted.

\section{Challenge systemic/institutionalised biases and prejudices}

Does the policy seek to "make for a better world"?

Think about whether the policy promotes 'business as usual' in relation to the chosen focus area or whether it helps challenge systemic/institutional biases which may be long-standing or which may have 'crept into' a particular organisation. These considerations may relate to a variety of inclusive practices within the school, including, but not limited to, recognition of various abilities, cultural capacities, and strengths and provision of adequate resourcing for priority areas. Such policy stances can serve as proactive ways of addressing various injustices, including in relation to race, religion, socioeconomic status, and sexual orientation.

\section{Harness the skills and expertise that exist beyond the school}

What information can be used to create and craft a policy that reflects best practice?

You will need to connect with research and the broader knowledge base available to ensure the policy is informed and factual. Schools will need to consider what academics, local businesses, and government representatives are doing with policy, especially when creating or updating policy. You might want to share policies with others so that schools can learn from each other.

\section{Create an action plan}

Do people within your school (staff, students) have a say over decisions that affect them?

A sense of agency and ownership will increase the likelihood that a policy is enacted well. Develop an action plan that recruits segments of the school community to help build your policy so that it is representative and reflective of the collective interest. 


\section{Create a communication tool}

Does the policy send a message to the school community? Is it an engaging message?

School policies offer an opportunity to articulate a message in a formal manner that demonstrates a school's drive and commitment to a particular issue or area. You may like to consider using policy updates as a communication tool. Another approach is to invite students to discuss policies with family and friends, present a school policy at a school assembly, create policy-related "homework", use parent and caregiver information evenings to highlight a topic raised in a school policy; and deliver an open community forum on a particular policy. Each of these approaches aim to embed the dissemination of policy in events that already occur within the day-to-day running of school. Remember, it is crucial to avoid tokenistic or inauthentic attempts to create and disseminate policy.

\section{Recognise the need for professional development and capacity building.}

Is the school and staff equipped to enact the policy

Professional development and capacity building should be a consideration in policy development and delivery. School leaders should avoid asking staff to create policy without sufficient training or expertise in policy development and enactment. Ways of achieving the successful uptake of a policy may also entail a school creating opportunities for learning and teaching about a particular policy topic.

\section{Concluding remarks}

This book provides a critical resource for schools and at the same time serves as an important opportunity for research translation. With over $70+$ contributors representing a vast number of countries and disciplinary areas, this book provides a practical and novel contribution to school policy and practice worldwide. The effective implementation of evidence-based policy is a hallmark of effective education, and we anticipate this book will provide impactful change in schools for years to come.

Dr Kelly-Ann Allen, PhD, Faculty of Education, Monash University and the Centre for Positive Psychology, Melbourne Graduate School of Education, The University of Melbourne

Professor Andrea Reupert, PhD, Faculty of Education, Monash University, Associate Professor Alan Reid, PhD, Faculty of Education, Monash University

Professor Ian Hardy, PhD, School of Education, Monash University

Professor Lindsay Oades, PhD, Centre for Positive Psychology, Melbourne Graduate School of Education, The University of Melbourne. 